\title{
ESTUDIO DE LAS NECESIDADES ALIMENTARIAS DE LOS REFUGIADOS EN LA CIUDAD DE GUAYAQUIL.
}

\section{STUDY OF THE FOOD NEEDS OF REFUGEES IN THE CITY OF GUAYAQUIL.}

Sergio Leonardo Pino Peralta, Mgs.

Magíster en Economía Agrícola y Desarrollo Rural (Ecuador)

Docente titular a tiempo completo de la Facultad de Ciencias Económicas de la

Universidad de Guayaquil, Ecuador. sergio.pino@ug.edu.ec

Hermes René Aguilar Azuero, Mgs. Magíster en Negocios Internacionales y Gestión en Comercio Exterior (Ecuador) Docente titular a tiempo completo de la Facultad de Ciencias Económicas de la

Universidad de Guayaquil, Ecuador. hermes.aguilara@ug.edu.ec

Alfonso Casanova Montero, PhD. Doctor en Ciencias Económicas (Cuba) Docente titular a tiempo completo de la Facultad de Ciencias Económicas de la Universidad de Guayaquil, Ecuador. alfonso.casanovam@ug.edu.ec

\section{ARTíCULO DE INVESTIGACIÓN}

Recibido: 15 de marzo de 2017

Aceptado: 1 de junio de 2017

ISSN: 1390-9320, Vol. 5, No. 1, febrero 2018 


\section{RESUMEN}

El objetivo de este artículo es realizar un estudio de las necesidades alimentarias de los refugiados y solicitantes de refugio en la ciudad de Guayaquil en el año 2015; así como determinar la situación nutricional de los beneficiarios con status de refugiados; estimar el ingreso familiar de los refugiados en Guayaquil; y, determinar la tasa de empleo de los refugiados en esa ciudad. El Estado ecuatoriano ha reconocido a 60.329 personas refugiadas en el país hasta septiembre de 2016. El $95 \%$ de ellos son ciudadanos colombianos. En promedio 418 personas cruzan la frontera en busca de protección internacional cada mes. Por otra parte, 233.049 personas han solicitado el reconocimiento de la condición de refugiado en el Ecuador, en su mayoría de Colombia, desde 1989 a 2016. Ante esta realidad notoria e ineludible que se presenta en el país, el presente trabajo de investigación pretende contribuir, para que se entienda desde una óptica socioeconómica y humana a los miles de refugiados que conviven en el territorio nacional, sus implicaciones dentro de la sociedad ecuatoriana y en especial la guayaquileña. La investigación concluyó que los refugiados que viven en la ciudad de Guayaquil no requieren ayuda alimentaria que provee el Estado y las organizaciones Internacionales, con el mismo énfasis de los que habitan en la zona fronteriza, ya que sus ingresos le permiten tener acceso a alimentación, vestuario, arriendo y tener beneficios como atención a salud, educación.

Palabras clave: refugiados, seguridad alimentaria, conflicto fronterizo, Plan Ecuador.

\section{ABSTRACT}

The aim of this article is realize a study of the food needs of the refugees and solicitors of refuge in the city of Guayaquil in the year 2015; as well as to determine the nutritional situation of the beneficiaries with refugees' status; to estimate the familiar revenue of the refugees in Guayaquil; and, to determine the rate of employment of the refugees in this city. The Ecuadoran State has recognized 60.329 refugee persons in the country until September, 2016. $95 \%$ of them is Colombian citizens. In average 418 persons cross the border in search of international protection every month. On the other hand, 233.049 persons have requested the recognition of the refugee's condition in the Ecuador, in the main of Colombia, from 1989 to 2016 . Before this well-known and unavoidable reality that

ISSN: 1390-9320, Vol. 5, No. 1, febrero 2018 
one presents in the country, the present work of investigation tries to contribute, in order that there are understood from a socioeconomic and human optics the thousands of refugees who coexist in the national territory, his implications inside the Ecuadoran company and especially the Guayaquil people. The investigation concluded that the refugees who live in the city of Guayaquil do not need food help that provides the State and the International organizations, with the same emphasis of those who live in the frontier zone, since his income allows him to have access to supply, wardrobe, rental and take benefits as attention to health, education.

Keywords: refugees, food safety, frontier conflict, Plan Ecuador.

\section{INTRODUCCIÓN}

El conflicto armado de Colombia que dura más de 50 años es la causa principal, por lo que muchos ciudadanos de ese país están solicitando asilo político al Ecuador. En el 2001, Alto Comisionado de las Naciones Unidas para los Refugiados (ACNUR), establece una operación regular de recepción, protección y soluciones duraderas para refugiados en las provincias de Pichincha, Sucumbíos e Imbabura.

La Seguridad Alimentaria "a nivel de individuo, hogar, nación y global, se consigue cuando todas las personas, en todo momento, tienen acceso físico y económico a suficiente alimento, seguro y nutritivo, para satisfacer sus necesidades alimenticias y sus preferencias, con el objeto de llevar una vida activa y sana" (Organización de las Naciones Unidas para la Alimentación y Agricultura -FAO, 1996)

El hambre y la desnutrición continúan persistiendo en un mundo de riquezas, situación repetidamente puesta de manifiesto tanto por países individuales como por la comunidad internacional. La erradicación de la pobreza extrema y el hambre es el primero de los ocho Objetivos de Desarrollo del Milenio de las Naciones Unidas, metas globales establecidas por los líderes mundiales en la Cumbre del Milenio llevada a cabo en Nueva York en septiembre de 2000. (FAO, 2004)

Entre las principales formas contemporáneas de movilidad se distinguen dos movimientos: los que involucran fines de residencia, que son la definición misma de la migración

ISSN: 1390-9320, Vol. 5, No. 1, febrero 2018 
internacional, y aquellos de tipo temporal, asociados con la fluctuación estacional de la actividad económica. Ambas formas comprenden, a su vez, a los retornos hacia los países de origen, a los desplazamientos forzados (refugiados y desplazados) y a la migración de indocumentados: todas ellas implican el cruce de largas distancias o entre países limítrofes.... (Martínez Pizarro, 1998)

Ecuador es el país latinoamericano con la mayor población de refugiados. Hasta septiembre de 2016, el Estado ecuatoriano ha reconocido a 60.329 personas refugiadas en el país. El $95 \%$ de ellos son ciudadanos colombianos. En promedio, 418 personas cruzan la frontera en busca de protección internacional cada mes. Además, 233.049 personas han solicitado el reconocimiento de la condición de refugiado en el Ecuador, en su mayoría de Colombia, desde 1989 a 2016. (ACNUR, 2016)

Entre las consecuencias para el Ecuador del conflicto interno colombiano y del Plan Colombia en la frontera están los miles de refugiados, el desplazamiento de familias enteras, el empobrecimiento de la población, la situación de marginalidad y la misma inseguridad. Se considera que la amenaza de mayor riesgo está en el sector fronterizo en vista de que "la fiebre del narcotráfico y sus nefastas consecuencias ya se apoderaron de la temperatura social de los habitantes del sector". Según fuentes oficiales como la Organizaciones Naciones Unidas (ONU) y la Presidencia de la República de Colombia, se calcula que en 21 de los 67 municipios fronterizos (de los departamentos de Nariño, Cauca, Caquetá y Putumayo) hay un total de 23.599 hectáreas de coca cultivadas del total nacional. (Moreano, 2006)

El programa contempló el registro y documentación, fortalecimiento del sistema de elegibilidad de Ecuador, documentación (pasaporte y visa de refugio) para refugiados reconocidos, distribución de paquetes de alimentos a solicitantes muy vulnerables por un plazo de 3 meses, distribución de kits para instalación de vivienda, apoyo con medicinas para la atención de salud, apoyo con útiles escolares para el ingreso a la escuela de niñas/os solicitantes de refugio y apoyo logístico a repatriaciones voluntarias.

En el 2002 se extiende la operación a las provincias de Esmeraldas, Carchi y a la Ciudad de Santo Domingo de los Colorados, se mantuvo el mismo programa de registro,

ISSN: 1390-9320, Vol. 5, No. 1, febrero 2018 
protección, asistencia humanitaria y soluciones durables. Ingresaron 6.600 nuevos solicitantes de refugio y fueron reconocidos 1.600 nuevos refugiados.

La asistencia alimentaria se distribuye a través de las agencias implementadoras de ACNUR aplicándose una guía de asistencia que prioriza a personas muy vulnerables como mujeres embarazadas, ancianos y niños lactantes, la gran mayoría se encuentra por debajo de la Canasta Vital Familiar y muy por debajo de la Canasta Básica Familiar lo que significa que más del $89 \%$ está bajo la línea de pobreza y bajo la línea de indigencia.

No obstante, las necesidades de alimentos son crecientes, en tanto y en cuanto, el número de familias colombianas va en aumento. Las estadísticas señalan que desde el año 2000, el número de solicitudes de asilo se incrementó de 252 a 7.299 en el 2003, Por ello, el ACNUR y el Programa Mundial de Alimentos (PMA) se encuentran empeñados en buscar una estrategia común que permita atender a esta población de refugiados y solicitantes de refugio que necesita este tipo de ayuda humanitaria.

El Estado ecuatoriano invierte cerca de 60 millones de dólares anuales para atender a los refugiados en el país, en términos de acceso a educación, salud y subsidio al gas de uso doméstico. Por su parte, Colombia ha colaborado con un millón de dólares para el desarrollo de proyectos en beneficio de la población refugiada, en la frontera norte básicamente. La cooperación internacional en materia de refugio colabora con 15 millones esto es apenas el $25 \%$ de lo que invierte año a año el Ecuador en estos rubros de atención.

Pero el número de personas que llegan al país, no coincide con el número de solicitudes de asilo. La clandestinidad es de al menos tres veces más que los solicitantes. Las autoridades ecuatorianas consideran que alrededor de 500.000 colombianos viven en el país, la gran mayoría, de manera clandestina, su presencia tiene sus orígenes en los procesos de migración forzada interna que vive Colombia.

El $60 \%$ de los asilados vive en áreas urbanas y que la mayoría del $40 \%$ restante permanece cerca de la frontera con Colombia, en regiones poco desarrolladas y aisladas, con limitados servicios básicos e infraestructura.

ISSN: 1390-9320, Vol. 5, No. 1, febrero 2018 


\section{REVISIÓN TEÓRICA}

Una de las obligaciones de los gobiernos del mundo, según los Tratados Internacionales y la Carta de la Organización de las Naciones Unidas es dar seguridades a quienes están en situación de refugiados dentro de su territorio nacional, para protección de sus derechos humanos y especialmente, de su vida.

Por esta razón se creó en el seno de las Naciones Unidas el UNHCR (UNITED Nations High Commissioner for Refugees) o ACNUR (Alto Comisionado de las Naciones Unidas para los Refugiados), que tiene como propósito brindar asistencia a los refugiados en el mundo y encontrar soluciones duraderas para ellos. Esta agencia fue creada para apoyar a los Estados a resolver el problema que vivían millones de refugiados que surgieron como consecuencia de la Segunda Guerra Mundial.

Actualmente el ACNUR presta asistencia a millones de refugiados, lamentablemente los conflictos y las crisis de refugiados no han cesado en el mundo y en el caso de América Latina el conflicto armado en Colombia ha dejado a más de 2 millones de desplazados.

Por tal motivo, este problema debe entenderse desde tres causas que explican la extensión del conflicto armado colombiano hacia Ecuador. En primer lugar, la franqueable geografía de la frontera ecuatoriana: 600 kilómetros de densa selva amazónica (Sucumbíos) y tupidos bosques tropicales (Esmeraldas), prácticamente imposibles de patrullar.

En segundo lugar, se menciona al Plan Colombia, que empujó a las Fuerzas Armadas Revolucionarias de Colombia (FARC) a las zonas fronterizas de Nariño y Putumayo.

En tercer lugar, se refiere a que durante décadas, Sucumbíos y Esmeraldas se vieron muy poco beneficiados por los servicios estatales, lo cual incrementó la vulnerabilidad de la zona.

Lo que empezó en la frontera norte, se ha diseminado en todo el país, siendo Guayaquil la cuarta ciudad con mayor cantidad de refugiados. Anualmente, el Ecuador junto con organizaciones privadas invierte 60 millones en ayuda a los refugiados, esto es, en raciones alimenticias (desayuno-almuerzo-merienda), asistencia médica y talleres de inserción laboral, en los puntos de asistencia social que dispone el ACNUR.

ISSN: 1390-9320, Vol. 5, No. 1, febrero 2018 
La ciudad de Guayaquil, da refugio a 2975 legales y 2.017 solicitudes en trámite, un total de 5.052 refugiados; a parte de la "población invisible" que son en igual proporción o más, de los cuales no se tiene registro alguno; sin embargo, cifras aproximadas de las autoridades del ACNUR se estima que hay cerca de 60.000 refugiados en la ciudad de Guayaquil que viven en condición de pobreza y exclusión social. Los Programas de ayuda mundial como el PMA y los que mantiene el Estado solo llegan a los refugiados legales y no llegan a materializarse para la mayoría que no se benefician de la condición de refugiado y tiene que sobrevivir con formas creativas y precarias de subsistencia.

Esto, ha traído consigo cierta xenofobia hacia los refugiados especialmente los colombianos que son considerados personas no gratas, ya que se los ha encontrado inmiscuidos en bandas delictivas, trata de blanca, extorsión y sicariato.

El Ecuador es el único país con una política pública en materia de refugio, existiendo en la ciudad de Guayaquil alrededor del $7 \%$ de las personas reconocidas como refugiadas provenientes de diferentes países del mundo. De ellos, el 99,8\% son de nacionalidad colombiana y el $0,20 \%$ son cubanos, afro-nigerianos y de Europa del Este.

Esta Política Nacional en materia de refugio que ha diseñado el gobierno se encuentra enmarcado en el Plan Nacional de Desarrollo, en su Capítulo de Política Exterior que asume que éste, como otros fenómenos migratorios, debe ser abordado desde la defensa y respeto a los Derechos Humanos para obtener resultados eficaces de impacto social.

Para ello, se establece un programa de Política Pública orientada a fomentar la inserción social de los refugiados en condiciones de dignidad y solidaridad. El Gobierno Nacional incentiva el Programa de Ciudades Solidarias, el cual actúa en coordinación con los Gobiernos locales y la sociedad civil.

Por otra parte, se lleva a cabo el Plan Ecuador en donde se destacan compromisos puntuales como:

- Reconocer tanto a refugiados como a las comunidades receptoras en situación de vulnerabilidad (mujeres, jóvenes, indígenas, etc.).

- Promover el acceso a oportunidades de desarrollo.

ISSN: 1390-9320, Vol. 5, No. 1, febrero 2018 
- Generación de ingresos y microcrédito para promover la integración socioeconómica de la población en situación de refugiado.

También incluye el Programa de Fronteras Solidarias que está bajo la responsabilidad del Plan Ecuador el cual consta de tres elementos:

- Registro Anticipado, como mecanismo de la condición de refugiado en Ecuador.

- La campaña de sensibilización sobre la problemática de refugio.

- El Plan Estratégico Regional de construcción de una zona de paz y desarrollo.

Alrededor del $60 \%$ de los refugiados en Ecuador se asientan en cascos urbanos, de hecho un 30\% de esta población se asienta en Quito, los demás viven en otras ciudades como Guayaquil, Cuenca y Santo Domingo. Cabe destacar que en el país no existen campos de refugiados, y existe libertad para que los mismos se desplacen por todo el territorio nacional con iguales derechos y responsabilidades que los ciudadanos ecuatorianos.

Las oficinas del ACNUR en la ciudad de Guayaquil, cuenta con cuatro puntos de asistencia alimentaria y social para los refugiados, las cuales están ubicadas en Bastión Popular, Isla Trinitaria, Guasmo y Fragata.

EI ACNUR, junto con organizaciones no gubernamentales como "Solidaridad Internacional" (HOYOS), y la Organización Hebrea para ayuda a inmigrantes y refugiados (HIAS), trabajan en la ciudad de Guayaquil repartiendo ayuda humanitaria a las personas más necesitadas que han llegado a la ciudad huyendo de la violencia y de amenazas contra su vida, esta ayuda puede consistir en albergue temporal, alimentos básicos y utensilios de cocina e higiene personal pues la intención es que todas estas personas logren estabilidad y autosuficiencia integrándose a la sociedad que los ha recibido.

Ecuador, al tener una política pública destinada a asistir en ayuda humanitaria a los miles de refugiados que han ingresado al país, justifica su responsabilidad de cumplir con los Tratados, Convenios y Compromisos Internacionales que se enmarquen como en este caso, dentro del respeto a los Derechos Humanos y a la libre movilidad de las personas; es suscriptor de la Convención de Ginebra de 1951 sobre Refugio, el Protocolo de 1967, la Declaración de Cartagena de 1984 y el Plan de Acción de México de 2004.

ISSN: 1390-9320, Vol. 5, No. 1, febrero 2018 
La movilidad humana cual fuera la razón de ser, constituyó en el país un lastre que millones de ecuatorianos la sufrió en carne propia, por esta experiencia y muchas razones más el Ecuador es un país benevolente y generoso con políticas públicas claras destinadas a mejorar las condiciones de vida de los refugiados, tanto es así; que el Gobierno Nacional tiene como meta el fortalecimiento del Plan Nacional del Buen Vivir, como interculturalidad, movilidad humana, derechos humanos, enfoque de género, atención adecuada a personas con discapacidad, cuidado ambiental, desconcentración, entre otros. Los cuales están consagrados en la Constitución de la República.

Cabe destacar que la situación de los refugiados en la ciudad de Guayaquil es diferente a la situación que se presenta en la frontera norte como Esmeraldas y Sucumbíos debido a que en Guayaquil es una ciudad donde existe mayor actividad económica, es la ciudad con una población de casi tres millones de habitantes siendo la mayor del país existiendo una actividad económica informal importante y de alguna manera han podido insertarse en la actividad comercial, mientras que en Esmeraldas es una ciudad que ha estado abandonada por las políticas públicas y las autoridades locales; en el mismo caso se encuentra Sucumbíos, por lo que los refugiados optan por adentrarse en el país a ciudades de mayor actividad económica como Guayaquil, Santo Domingo, Quito y Cuenca.

Según la oficina del ACNUR en Guayaquil, la cifra de refugiados ilegales asciende a 60.000 personas, lo que representaría más o menos el $2 \%$ con respecto a la cifra total de habitantes de la ciudad, lo cual justifica plenamente esta investigación.

\section{MATERIALES Y MÉTODOS}

El trabajo de investigación es de tipo descriptiva, pues se formuló una encuesta para realizar el estudio de las necesidades alimentarias de los refugiados que se encuentran en la ciudad de Guayaquil.

Una vez formulada las preguntas de la encuesta que se aplicó a los refugiados en la ciudad de Guayaquil, se realizó la toma o recolección de la información en forma ordenada para analizarla y representarla en un conjunto de datos o base de datos en tablas de Excel con el fin de describir apropiadamente las características de este conjunto; para ver en qué

ISSN: 1390-9320, Vol. 5, No. 1, febrero 2018 
medida los datos se agrupan o dispersan en torno al tema central, determinando los resultados de la investigación.

Asimismo, se determinó la población total de refugiados y se calculó el tamaño de la muestra, con los siguientes datos:

Tabla 1. Población total de refugiados y tamaño de la muestra.

\section{POBLACIÓN Y MUESTRA}

\begin{tabular}{clc}
\hline Signo & \multicolumn{1}{c}{ Significado } & Valores \\
\hline $\mathrm{n}$ & Muestra & 61 \\
$\mathrm{Z}$ & Nivel de confianza & $(1,96)^{\wedge^{2}}$ \\
$\mathrm{p}$ & Variabilidad positiva & 0,5 \\
$\mathrm{q}$ & Variabilidad negativa & 0,5 \\
$\mathrm{~N}$ & Tamaño de la población & 5.052 \\
e & Precisión de error & $(0,05)^{\wedge^{2}}$ \\
\hline
\end{tabular}

TOTAL Encuestas

61

Fuente: Elaboración propia.

\section{ANÁLISIS DE LOS RESULTADOS Y DISCUSIÓN}

La investigación de campo se realizó en los sectores donde, según información proporcionada por el ACNUR existe presencia de refugiados distribuidos en la parroquia Febres Cordero en un $18 \%$, Ximena con un $26 \%$, parroquia 9 de octubre con el $13 \%$ y la parroquia Tarqui con el $43 \%$ del total, lo que el análisis demuestra que el mayor porcentaje de refugiados se encuentran en las zonas urbano marginales como Bastión Popular, entrada de la 8, Voluntad de Dios, pertenecientes a la parroquia Tarqui.

ISSN: 1390-9320, Vol. 5, No. 1, febrero 2018 


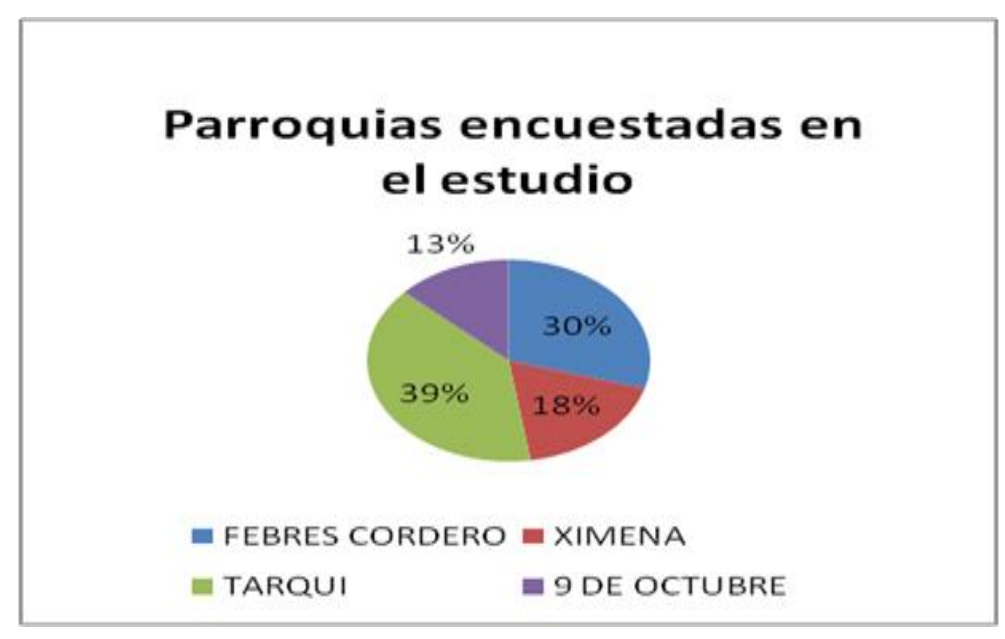

Gráfico 1. Parroquias encuestadas en el estudio.

Fuente: elaboración propia.

El estatus o condición de refugiado es otorgado en las oficinas del ACNUR, ubicadas en el edificio del Gobierno Zonal de la ciudad de Guayaquil, luego de haber hecho un análisis de su situación, según los datos recogidos las personas que se encuentran con el estatus de refugiados tienen en promedio dos años y siete meses aproximadamente de permanencia en el país.

Es importante el entorno familiar en que se desenvuelve la persona refugiada, ya que de ello depende en gran medida su adaptación al medio y posterior desarrollo. El estudio muestra que los grupos etarios corresponden al $6 \%$ entre edades que van de 0 a 5 años, el $12 \%$ en edades de 5 a 12 años, el 19\% en edades de 12 a 20 años y el 63\% corresponden al grupo de 20 a 45 años, siendo este último grupo, el de mayor porcentaje por edad de la familia refugiada. También, el estudio indica que la cantidad de hijos por familia de los refugiados que se encuentran en la ciudad de Guayaquil es de 0,97 hijos.

ISSN: 1390-9320, Vol. 5, No. 1, febrero 2018 


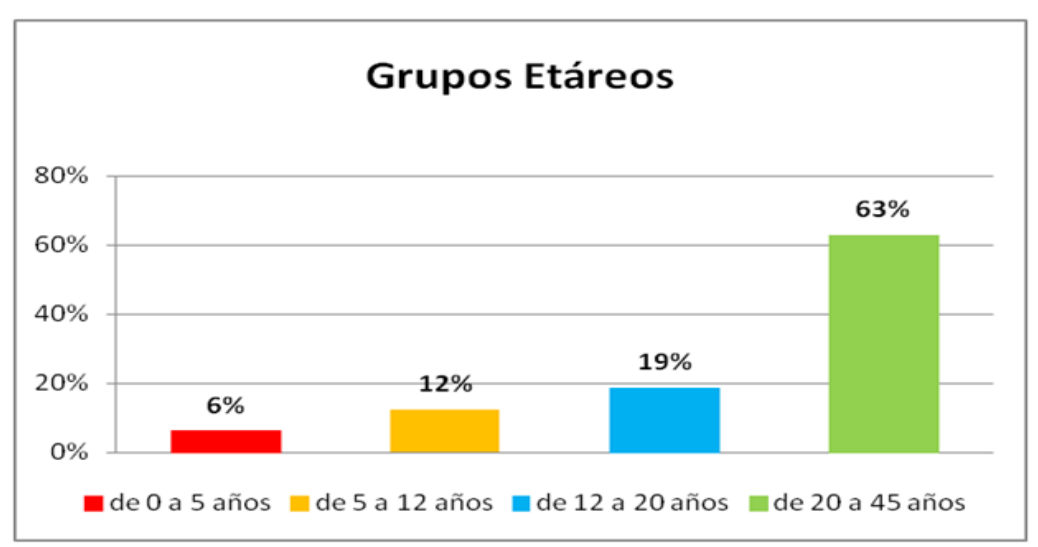

Gráfico 2. Estudio de los grupos etarios.

Fuente: elaboración propia.

Las actividades que realizan los hijos de los refugiados se las puede dividir en dos segmentos: la primera es la dedicación al estudio con el $61 \%$ y la otra, es aquella en que los hijos se dedican a ayudar a sus padres en actividades que generen ingresos como recolección de chatarra, plásticos, venta de caramelos en buses, especialmente en los sectores marginales como Monte Sinaí, Tierra de los Pobres, lo cual alcanza el 39\%.

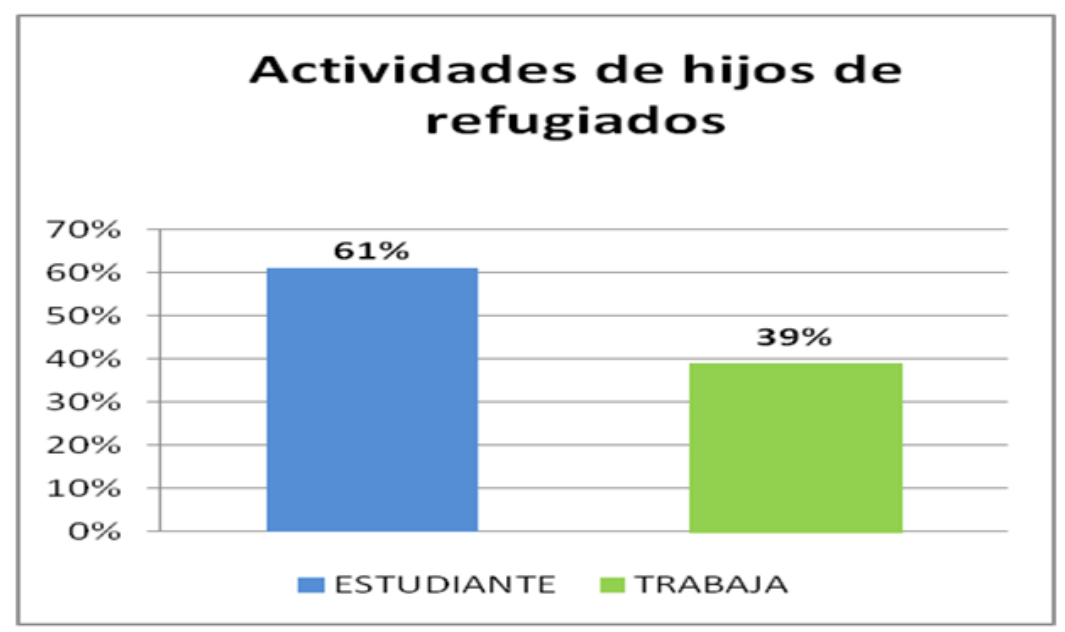

Gráfico 3. Actividades de hijos de refugiados.

Fuente: elaboración propia. 
Asimismo, el mayor porcentaje de refugiados que se encuentran en la ciudad de Guayaquil corresponde al sexo masculino con un $74 \%$ mientras que el $26 \%$ es para el sexo femenino. La edad promedio del refugiado es de 35 a 40 años, como edad máxima.

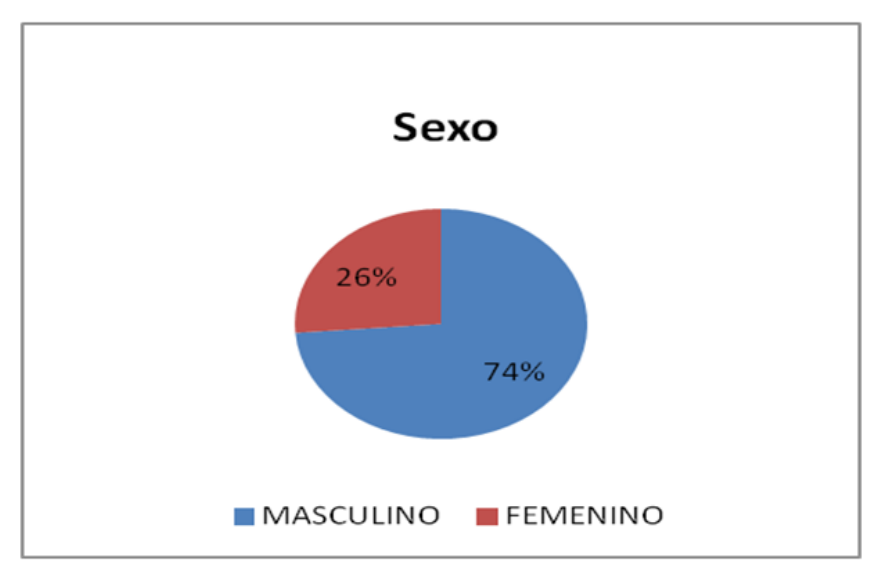

Gráfico 4. Sexo de los refugiados.

Fuente: elaboración propia.

El $62 \%$ de los refugiados en la ciudad de Guayaquil no tiene ningún tipo de instrucción ya que vienen de las zonas rurales de Colombia, el $36 \%$ tiene finalizado sus estudios primarios y el $2 \%$ apenas han completado la secundaria, mientras que a nivel universitario no hubo registros.

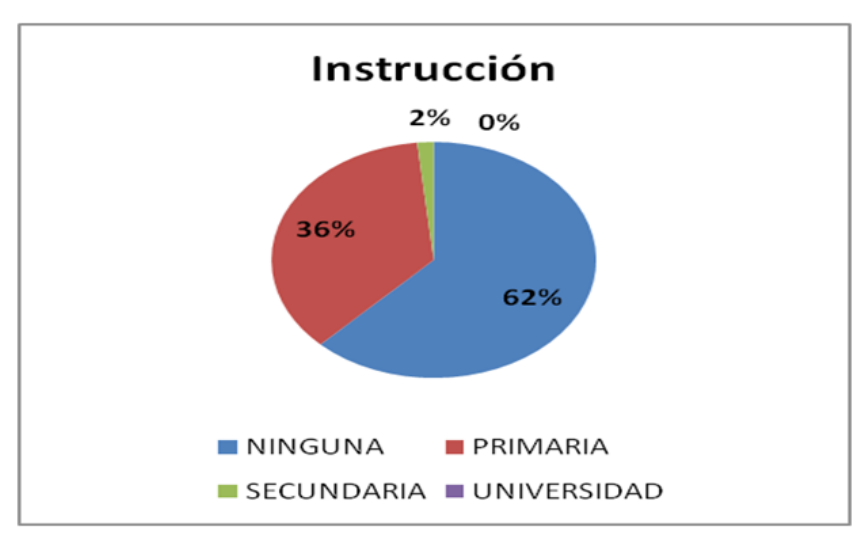

Gráfico 5. Instrucción de los refugiados.

Fuente: elaboración propia.

ISSN: 1390-9320, Vol. 5, No. 1, febrero 2018 
Las actividades económicas que realiza el refugiado para subsistir son diversas entre las cuales se destaca el comercio, compra-venta de ropa, artículos de limpieza personal, etc., con el $52 \%$, seguido de ayudantes de panadería con el $20 \%$, ayudantes de comedores con el $18 \%$, trabajos de construcción con $10 \%$.

\section{Actividad económica}

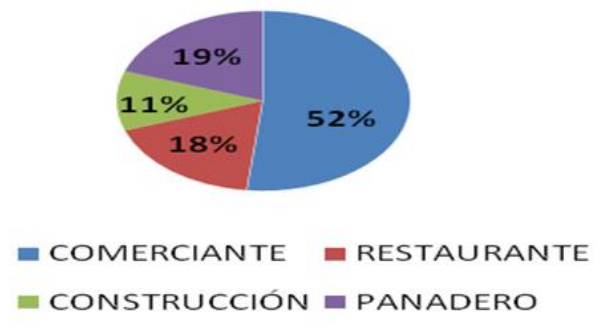

Gráfico 6. Actividad económica de los refugiados.

Fuente: elaboración propia.

Estas actividades económicas le proporcionan en promedio al refugiado un ingreso mensual de USD 461,6 con lo cual, logra adquirir los víveres para su subsistencia.

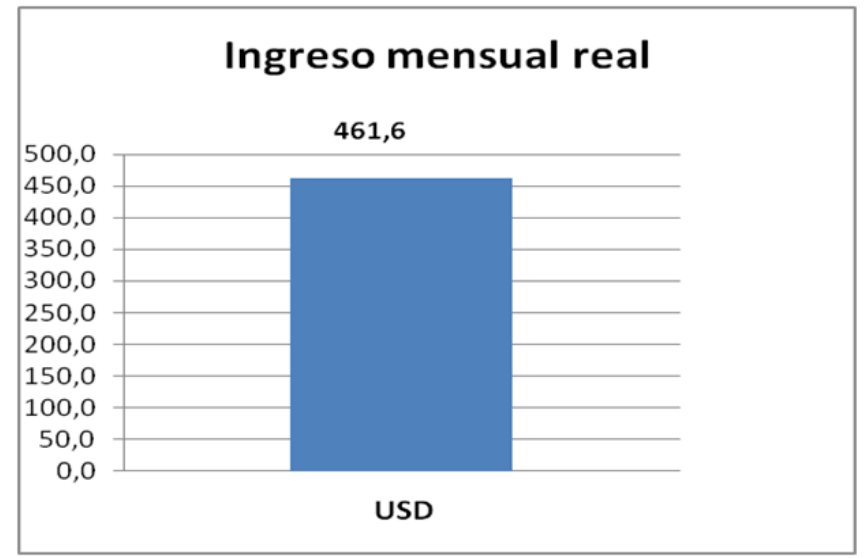

Gráfico 7. Ingreso mensual real de los refugiados.

Fuente: elaboración propia. 
El gasto familiar por mes se calculó con base en el pago de los servicios básicos de agua, luz, vestimenta, alimentación, arriendo y otros rubros, que juntos suman USD 274,6. Del ingreso obtenido, el $1 \%$ se gasta en agua potable, en energía eléctrica el $2 \%$, vestimenta el $13 \%$, alimentación el $51 \%$, arriendo $25 \%$ y otros gastos el $8 \%$, en este caso el gasto de mayor valor es el de la alimentación. Los refugiados para poder tener un techo donde vivir gastan en alquiler de vivienda un promedio de USD 70 mensuales.

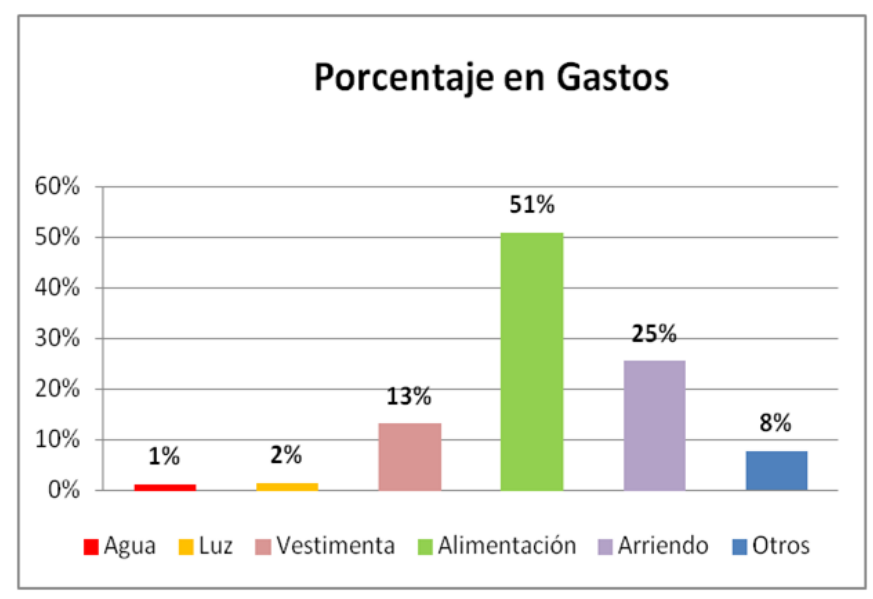

Gráfico 8. Gastos de los refugiados.

Fuente: elaboración propia.

El costo en alimentación que se determinó, fue de USD 92,26 calculado por la ayuda que reciben de la Iglesia Católica del Monseñor, ubicada en el Monte Sinaí. Los refugiados aquí reciben una ración alimenticia al día, especialmente mujeres y niños, esta ayuda hace que el costo en alimentación sea menor en comparación con el costo real.

ISSN: 1390-9320, Vol. 5, No. 1, febrero 2018 


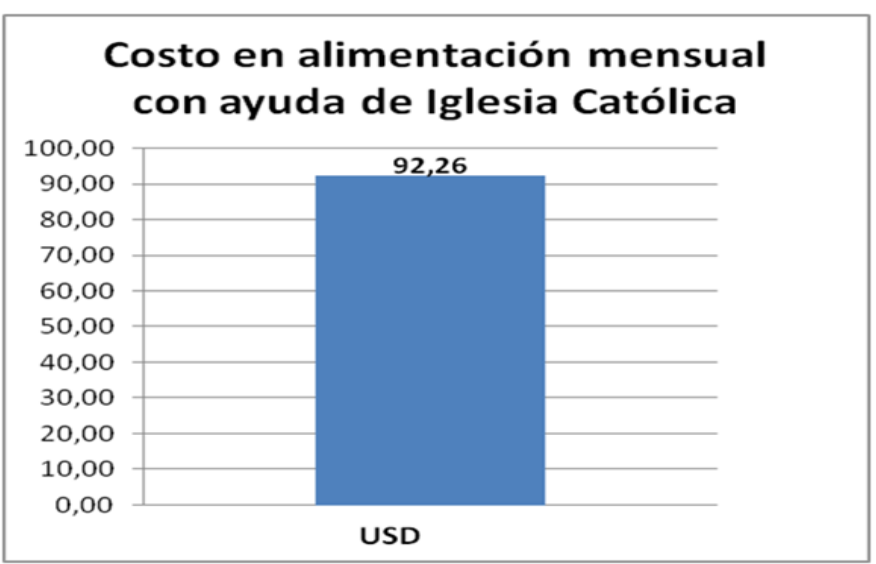

Gráfico 9. Costo en alimentación mensual con ayuda de la Iglesia Católica.

Fuente: elaboración propia.

El valor por alimentación de los refugiados es de USD 140 mensual, calculado para aquellos que no reciben ayuda alimenticia de parte de la Iglesia Católica.

La muestra tomada a los refugiados, determinó que en la ciudad de Guayaquil no reciben ayuda alguna de programas de alimentación por parte del Estado, ni de Organizaciones Internacionales ya que su condición es diferente a los desplazados que se encuentran en la zona fronteriza con Colombia. La Iglesia Católica ubicada en el Monte Sinaí, de la Parroquia Tarqui proporciona ayuda alimentaria al $29,50 \%$ de refugiados, especialmente mujeres y niños en condición de vulnerabilidad. 


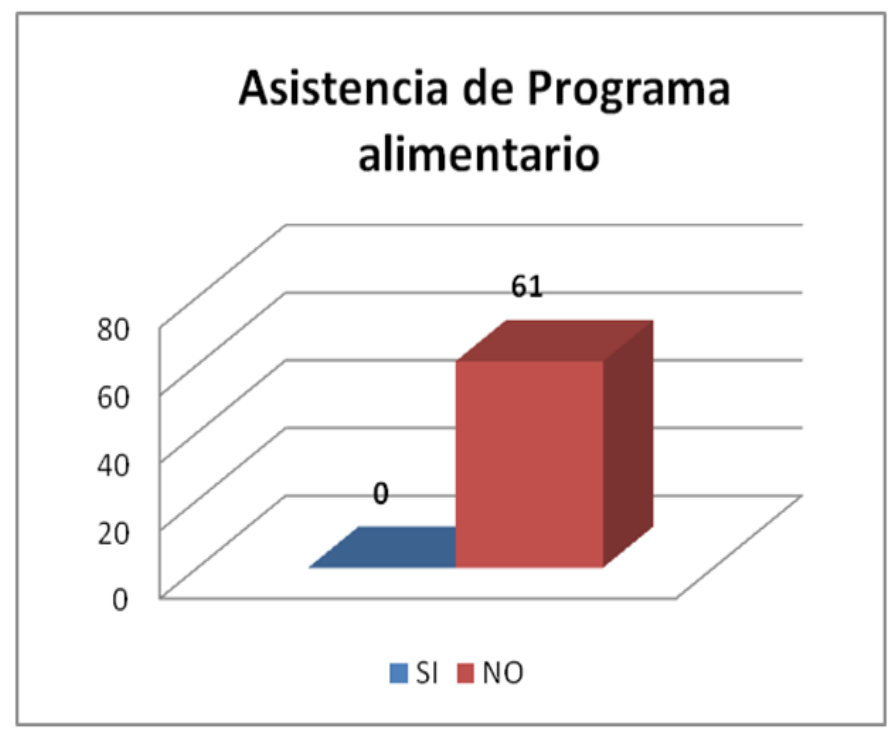

Gráfico 10. Asistencia de programa alimentario.

Fuente: elaboración propia.

La proporción de alimentos que consumen y compran a diario los refugiados están el arroz en un $60 \%$, carne $9 \%$, aceite $7 \%$, pan $4 \%$, granos $3 \%$, verduras $3 \%$, leche $3 \%$, huevos $3 \%$, pescado $2 \%$, legumbres $2 \%$, lácteos $1,5 \%$, frutas $1 \%$, queso $1 \%$ y jabones $1 \%$.

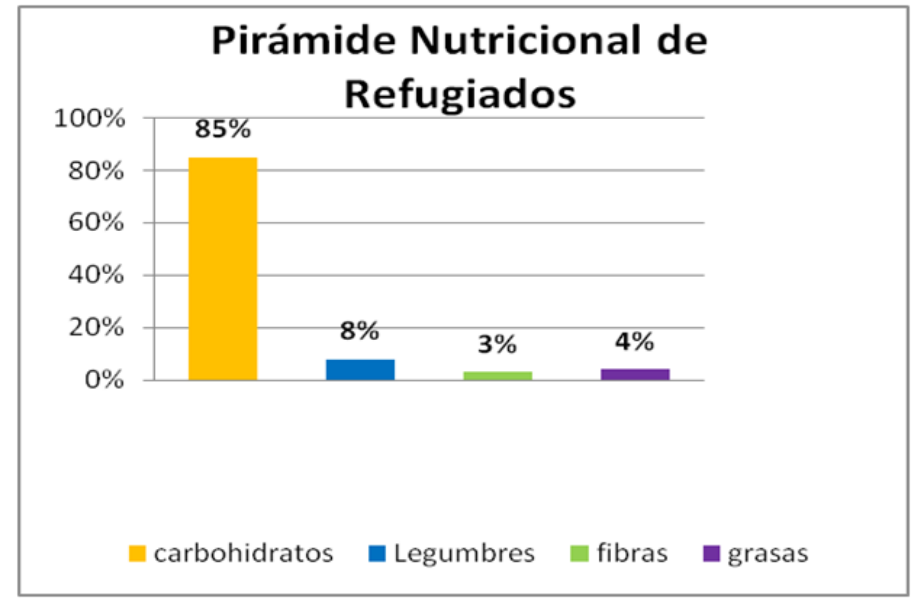

Gráfico 11. Pirámide Nutricional de Refugiados.

Fuente: elaboración propia.

ISSN: 1390-9320, Vol. 5, No. 1, febrero 2018 
Las enfermedades más recurrentes que afectan a la población de refugiados y que alguna vez se le diagnosticó, son la gripe con $77 \%$, seguido del dengue con el $20 \%$ y el asma con el $3 \%$ de afectados. Estas afectaciones son atendidas en los centros hospitalarios del sector público y privado. Del total de la muestra, el $58 \%$ respondieron que acuden al servicio público, el $35 \%$ se auto medican y solamente el $6 \%$ acuden a un centro privado. Por último, el $100 \%$ de los encuestados, indican que no han recibido ningún tipo de financiamiento o crédito ya sea del sector público o privado.

Los refugiados que se encuentran establecidos dentro de nuestro territorio nacional, han sido víctimas de constantes agresiones y maltratos, producto de los factores estigmatizantes que aquejan a nuestra sociedad lo que ha producido en la misma, sentimientos de odio y recelo a tal punto de crear casos de discriminación y xenofobia por parte de la población ecuatoriana. (Toledo, 2014)

Surge la interrogante y muchos se preguntarán, porqué el Estado gasta 60 millones anuales en atención a los refugiados, en atención a un problema ajeno pero; que involucra indirectamente al país, con este dinero se podría construir más escuelas del milenio, hospitales y atender a la población más vulnerable, la explicación no es fácil; pasando por la cultura generosa del pueblo ecuatoriano, es el único país que en su Constitución tiene políticas de Estado destinadas a garantizar la salud y vida de los refugiados, además de estar comprometido con la Carta de las Naciones Unidas de garantizar los derechos de los refugiados.

Aunque las acciones del Estado por mejorar las condiciones de los refugiados en el país son evidentes, lo cual hay que reconocerlo; están enfocadas en las zonas fronterizas de Esmeraldas y Sucumbíos; a la vez que surge un problema como consecuencia de que los refugiados buscan las grandes ciudades, donde ellos creen que tienen mejores oportunidades de progreso como Guayaquil, que siendo la ciudad más poblada del país con más de 2 millones de habitantes.

Una vez que los refugiados llegan a las grandes ciudades, se dispersan por lo que su búsqueda y localización es incierta, dificultando la ayuda del Estado en la planificación y ejecución de los programas de asistencia.

ISSN: 1390-9320, Vol. 5, No. 1, febrero 2018 
La llegada de refugiados enfrenta un problema social ya que según el ACNUR existen 5.052 personas legalmente con estatus de refugiado, pero esa cifra en realidad se triplica o aún más, esta población invisible de ilegales ha provocado un clima xenofóbico en la sociedad ecuatoriana, debido a que estas personas se los ha encontrado liderando bandas delictivas, por eso se hace necesario el pasado judicial y deportar a estos individuos que son un peligro para la sociedad. Esta población "invisible", no quiere dejarse ver, por el temor a ser deportado aun cuando existan programas sociales que vayan destinados a mejorar sus condiciones de vida.

Es notorio ver, que dentro de la ciudad de Guayaquil ciertos refugiados especialmente los colombianos viven en mejores condiciones que los propios ecuatorianos, esto es debido a que son dinámicos, aventureros y emprendedores,

Finalmente, se ha comprobado mediante el análisis que la gran mayoría de refugiados que viven en la ciudad de Guayaquil se encuentran en las zonas urbanas marginales, tal es el caso de Los Guasmos 26\% (Parroquia Ximena) y Bastión Popular 43\% (Parroquia Tarqui).

Una vez prolongado el tiempo de las personas en condición de refugiados, estas optan por legalizar su situación para conseguir su permanencia indefinida ya que el país le ofrece mejores oportunidades que la de su país de origen.

El subempleo gira en torno a las actividades de subsistencia que realiza: el $52 \%$ se dedica al comercio de bienes y de servicios; $10 \%$ a la construcción, $18 \%$ a la preparación de alimentos; y, el 205 a la elaboración de panes y dulces. Todas estas actividades informales económicas se realizan sin seguridad social.

Los refugiados no reciben ayuda del Programa Mundial de Alimentos financiado por la ONU, ya que estos programas se encuentran focalizados en las provincias fronterizas con Colombia, más bien reciben ayuda alimenticia de las iglesias como la iglesia de Bastión Popular que atiende a las mujeres embarazadas y niños.

A pesar de que no están bajo la línea de pobreza, los refugiados se ven afectados en su salud y por lo menos un $77 \%$ ha recibido atención médica en los últimos tiempos.

ISSN: 1390-9320, Vol. 5, No. 1, febrero 2018 


\section{CONCLUSIONES}

Es importante demandar a que Colombia actúe de manera más solidaria con sus connacionales desplazados en territorio ecuatoriano, fomentando programas de desarrollo, incrementando la presencia del Estado en la zona fronteriza y aumentar los recursos económicos destinado a la ayuda humanitaria, que son apenas de 1 millón de dólares, mientras Ecuador destina 60 millones anuales para paliar el hambre y miseria por la que pasan los refugiados.

Legalizar e implementar los acuerdos de paz firmados en La Habana, Cuba, entre el Gobierno Colombiano del Presidente Juan Manuel Santos y los Jefes Guerrilleros para terminar con esta guerra inhumana que han dejado miles de muertos y ya casi 3 millones de desplazados. Se recomienda implementar nuevos filtros de ingreso en la frontera con Colombia que generen confianza para que las personas a quienes se les conceda el estatus de refugiado gocen de credibilidad.

Es necesario, que en la ciudad de Guayaquil las Autoridades del ACNUR logren articular la presencia del Programa Mundial de Alimentos y demás organizaciones encargadas de velar por los refugiados; tomando en consideración a las personas más vulnerables como mujeres y niños.

\section{REFERENCIAS BIBLIOGRÁFICAS}

ACNUR. (2000). Manual de Procedimientos y criterios para determinar la condición de refugiado. Quito.

ACNUR. (2008). Estadísticas sobre refugiados, solicitantes de asilo y otras personas bajo la competencia del ACNURen América Latina. Quito.

ACNUR. (2009). Acceso a servicios básicos de la población refugiada. Quito.

ACNUR. (2009). Políticas del ACNUR sobre la protección y las soluciones de los refugiados en zonas urbanas. Quito-Ecuador.

ACNUR. (2010). Situación del Ecuador. Ginegra,Suiza: Graphic Designer.

ACNUR. (2011). La Protección Internacional de refugiados en las Américas. QuitoEcuador: Mantis Comunicación.

ISSN: 1390-9320, Vol. 5, No. 1, febrero 2018 
ACNUR. (8 de diciembre de 2016). Agencia de las Naciones Unidas para los Refugiados. Obtenido de http://www.acnur.org

Acosta, A. (2006). Breve Historia Económica del Ecuador. Quito: Corporación Editora Nacional.

Aguas, P. (01 de Marzo de 2013). Ecuador Inmediato.com. Recuperado el Lunes de Mayo de 2013, de Ecuador Inmediato.com: http//www.ecuadorinmediato.com

Alison Nerner, A. C. (2002). Entre la Ley y la Realidad; La situación actual de los refugiados colombianos en el Ecuador. Quito.Ecuador.

Alonso, J. (2004). Emigración,Pobreza y Desarrollo. Madrid: La Catarata.

Asamblea Nacional Constituyente. (2008). Constitución de la Republica del Ecuador. Quito: Editora Nacional.

Banco Central del Ecuador. (2011). Remesas. Quito.

Benalcázar, P. (2009). El ABC de la Movilidad Humana en el Ecuador. Quito.

Benalcázar, P. (2013). Constitución, políticas públicas y movilidad humana. Quito.

Briscoe, I. (2008). Conflictos en la frontera: Las nuevas zonas calientes en América Latina. Madrid.

Carrere, R. (1999). Deforestación y monocultivos forestales en Ecuador. Quito.

Clirsen. (2003). Situación del cambio en el uso del suelo en el Ecuador. Quito.

Comisión Económica para América Latina y el Caribe. (2001). Vulnerabilidad y Medio Ambiente. Chile.

Dirección Nacional Forestal. (2003). Sitema de Control y Supervisión del Aprovechamiento de la Madera. Quito.

El Comercio. (2012). En los últimos 5 años las remesas se mantienen a la baja. Lideres, 29.

El Telégrafo. (2012). Las microempresas sacan de la pobreza a refugiados en Ecuador. El Telégrafo, 15-16.

FAO. (2004). Política de Desarrollo Agrícola, conceptos y principios. Roma: Dirección de publicaciones, FAO.

Flores Beltrán, C. I. (2008). Los refugiados y el asilo político en el Ecuador. Quito: Jaen.

ISSN: 1390-9320, Vol. 5, No. 1, febrero 2018 
Fundación Escalabriniana. (2011). El refugiado es vulnerable en Ecuador. Quito.

Fundación Jatún Sacha. (2000). Visión del Manejo y Conservación de los recursos naturales del Ecuador. Quito.

Fundación Real Instituto Elcano de Estudios Internacionales y Estratégicos Pricípe de Vergara. (2008). Remesas, Pobreza y Desigualdad: Caso Ecuador. Madrid: Real Instituto Elcano.

Fundación Regional de Asesoría en Derecho Humano. (2005). Los desplazados colombianos en Ecuador. Bogotá,Colombia.

Fundación Regional de Asesoría en Derechos Humanos. (2005). Volver a Empezar. Testimonios de vida y refugio. Quito.

Fundación Regional de Asesoría en Derechos Humanos. (2013). Políticas públicas y movilidad Humana en el escenario constitucional ecuatoriano. Quito: El Comercio.

Garrido, M. (20 de Junio de 2012). Ecuador,Refugiados. Ecuador: El más solidario en refugiados, pág. 16.

González, L. (2008). Fronteras en el Limbo. El Plan Colombia en el Ecuador. Quito.

INIAP. (2003). Proyectos de Desarrollo agroforestal en la Amazonía y Esmeraldas. Quito.

Martínez Pizarro, J. (1998). Dos artículos peregrinos sobre migración internacional. Revista del Fondo de Población de Naciones Unidas, 47.

Mejía, D. (2009). Intervenciones locales en Seguridad Ciudadana. En B. Carrión, Seguridad en la Frontera Norte (pág. 178). Quito: Cervantes.

Ministerio de Inclusión Social. (2010). Trata, tráfico, refugio y grupos de atención prioritaria en la migración(mujeres, niños y niñas) Ciudades Solidarias. Quito.

Ministerio de Relaciones Exteriores de Ecuador. (2006). Plan Nacional de Política Exteior. Quito-Ecuador.

Ministerio de Relaciones Exteriores, Comercio e Integración. (2008). Política del Ecuador en materia de refugiados. Quito.

Ministerio del Interior. (miércoles de Febrero de 2013). Refugiados en el Ecuador. Protección Internacional a los refugiados en Ecuador, otro reto del Ministerio del Interior para el 2013, pág. 14.

Molina, C. (2009). Cooperación internacional al desarrollo y refugio en la frontera norte. Quito.

ISSN: 1390-9320, Vol. 5, No. 1, febrero 2018 
Moreano, H. (2006). Las implicaciones del conflicto interno colombiano para las fronteras del Ecuador, Perú, Brasil y Venezuela, 2000-2005. ICONOS, 161-170.

Naciones Unidas. (2011). La proteción internacional de refugiados en las Américas. QuitoEcuador: Mantis Comunicación.

Organización de las Naciones Unidas para la Alimentación y Agricultura -FAO. (1996). Cumbre Mundial de la Alimentación (CMA). LSituación de la Seguridad Alimentaria Munidal (pág. 18). Roma: Editoral FAO.

Organización Internacional para las Migraciones. (2011). Protección de Refugiados. Ginebra-Suiza.

Organización Internacional para las Migraciones(OIM). (2011). Mejora en Gestión Fronteriza en la Región Andina. Quito-Ecuador.

Organización Mundial de Salud. (2010). Informe sobre la salud en el mundo. OMS. Ginebra,Suiza: Graphic Designer.

Pérez, C. (2003). Globalización, migración y derechos humanos. Apartados Andinos, 15.

Pontón, D. (2006). Violencia en frontera: una perspectiva desde la seguridad ciudadana. Quito.

Programa Mundial de Alimentos. (2010). Informe de la evaluación a profundidad de la seguridad alimentaria y nutricional en la población colombiana refugiada en el Ecuador y de la población acogida. Quito: Nacional.

Red Andina de Migraciones. (2009). Foro Regional sobre Migración, Derechos Humanos y Política Pública en la Región Andina. Quito-Ecuador.

Registro Oficial. (2010). Ley Orgánica de Educación Superior. Quito: Editora Nacional.

Rizzo. (2000). Situación forestal y comercial del Ecuador. Quito.

Rojas, M. C. (2007). Efectos de la regionalización de la política de seguridad democrática para el desplazamiento en las fronteras de Colombia. 23-24.

Superintendencia de Bancos y Seguros del Ecuador. (2011). Remesas y Sistema Financiero. Quito.

Toledo, S. (2014). Consecuencias del incremento de refugiados colombianos y su impacto en ámbito económico, social y político en Ecuador. Quito, Pichincha, Ecuador: Universidad de las Américas.

ISSN: 1390-9320, Vol. 5, No. 1, febrero 2018 
Universidad Politécnica Salesiana sede Quito. (2011). Estudio de los efectos psicológicos provocados por la situación de refugio en niños/as de nacionalidad colombiana que se encuentran en edad escolar. Quito-Ecuador.

Universidad Andina Simón Bolívar. (2004). Desplazamiento forzado y refugio. Aportes Andinos $N^{\circ} 8,11$.

Velásquez, E. (2007). La Governance de la seguridad ciudadana.Hacia una propuesta operacional. Florencia: Red URBAL.

Verney, M.-H. (2010). Colombianos refugiados en Ecuador. Bogotá, Colombia.

Villareal, B. (2006). Situación laboral de los solicitantes de refugio a partir de la implementación del Plan Colombia. Revista de Derecho Nº UASB, 15-16.

Vinueza, C. (2001). El bosque en el Ecuador,Una visión Transformadora. Quito. 